\title{
CADAVERIC STUDY ON THIRD HEAD OF BICEPS BRACHII- INCIDENCE IN THE SOUTH INDIAN POPULATION
}

\author{
Sujatha K1, Bernard Ritchie ${ }^{2}$, Shakuntala Rao ${ }^{3}$, H. R. Krishna Rao ${ }^{4}$ \\ ${ }_{1}^{1}$ Assistant Professor, Department of Anatomy, PES Institute of Medical Sciences and Research, Kuppam. \\ ${ }^{2}$ Tutor, Department of Anatomy, PES Institute of Medical Sciences and Research, Kuppam. \\ 3Professor, Department of Anatomy, PES Institute of Medical Sciences and Research, Kuppam. \\ ${ }^{4}$ Professor and HOD, Department of Anatomy, PES Institute of Medical Sciences and Research, Kuppam.
}

ABSTRACT

\section{BACKGROUND}

Biceps brachii belongs to the flexor group of muscle in the arm. It is the only flexor of the arm which crosses the shoulder and the elbow joint. It has two heads long and short head which originates from the supraglenoid tubercle of scapula and coracoid process respectively. They together form a common tendon and are inserted into the radial tuberosity.

The aim of the present study is to observe the variations in the origin, insertion and additional heads of biceps brachii muscle.

\section{MATERIALS AND METHODS}

The present descriptive study was done on 50 adult formalin fixed cadaver limbs $(n=100)$ consisting of 50 left and 50 right upper limbs, used for routine dissection and teaching purposes for the first-year medical students in the Department of Anatomy, PESIMSR College, Kuppam. The cadaver group consists of cadavers from South India.

\section{RESULTS}

The third head of biceps brachii was observed in one left upper limb of the 100 limbs and belonged to a male cadaver.

\section{CONCLUSION}

Third head of biceps brachii is a common variation with different incidence in different population. The incidence in the south Indian population is $1 \%$, but still this variation cannot be neglected as it is clinically important for the clinicians to have knowledge of such variation.

\section{KEYWORDS}

Biceps Brachii, Incidence, Third Head, South India.

HOW TO CITE THIS ARTICLE: Sujatha K, Ritchie B, Rao S, et al. Cadaveric study on third head of biceps brachii- Incidence in the South Indian population. J. Evolution Med. Dent. Sci. 2018;7(02):211-213, DOI: 10.14260/jemds/2018/47

\section{BACKGROUND}

The biceps brachii muscle belongs to the flexor group of muscle in the arm. It is the commonest muscle in the body to show variations with respect to its origin, insertion, nerve supply and number of heads. Usually, it has two heads long and short head originating from the supraglenoid tubercle of scapula and from coracoid process of scapula. The heads form a common tendon and are inserted on to the radial tuberosity. It mainly contributes to flexion and supination of the forearm; innervated by the musculocutaneous nerve and supplied by brachial and anterior circumflex humeral artery. ${ }^{1}$

The knowledge of such additional heads and associated variations in the architecture of the surrounding region is important, they can produce clinical symptoms by comprising surrounding neurovascular bundle. ${ }^{2}$

Variations of third head of biceps may present as a group of accessory fascicles arising from the coracoid process, the pectoralis major tendon, head of humerus, articular capsule of humerus or from shaft of humerus itself.

'Financial or Other Competing Interest': None.

Submission 23-11-2017, Peer Review 20-12-2017,

Acceptance 26-12-2017, Published 08-01-2018.

Corresponding Author:

Dr. Sujatha $K$,

\#96, Eurosion Block, Marikuppam-563119.

E-mail: sujathambbs@gmail.com

DOI: $10.14260 /$ jemds $/ 2018 / 47$

\section{(c) $(\mathbf{1})$}

The most common variation is a third head but four, five or even seven heads have been reported. ${ }^{3}$

\section{MATERIAL AND METHODS}

This descriptive study, Upper limb of the 50 cadavers, used for routine dissection from the Department of Anatomy, PESIMSR, Kuppam were observed for variations in origin, insertion and additional heads. The dissection procedure was as per the Cunningham's Manual of Practical Anatomy.

\section{RESULTS}

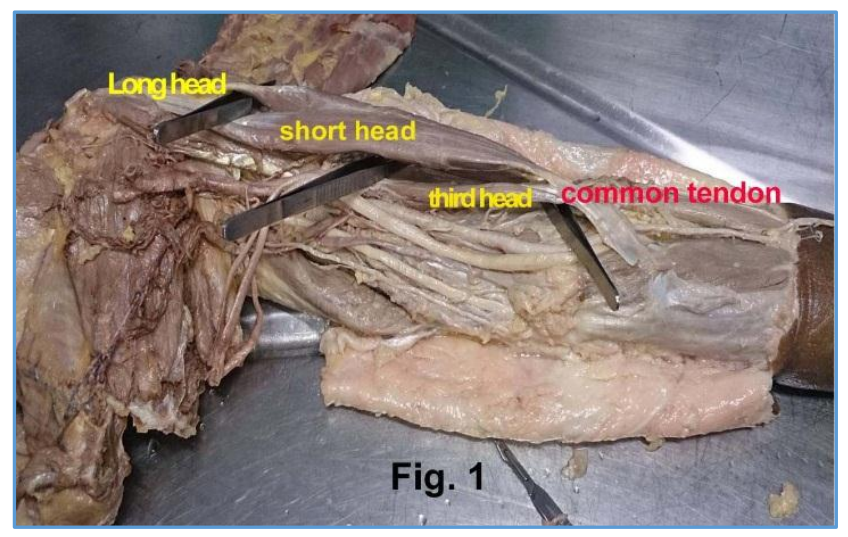

Figure 1. Third Head of Biceps Brachii Incidence being 1\% was Observed in only One Upper Limb of the Left Side of a Male Cadaver 


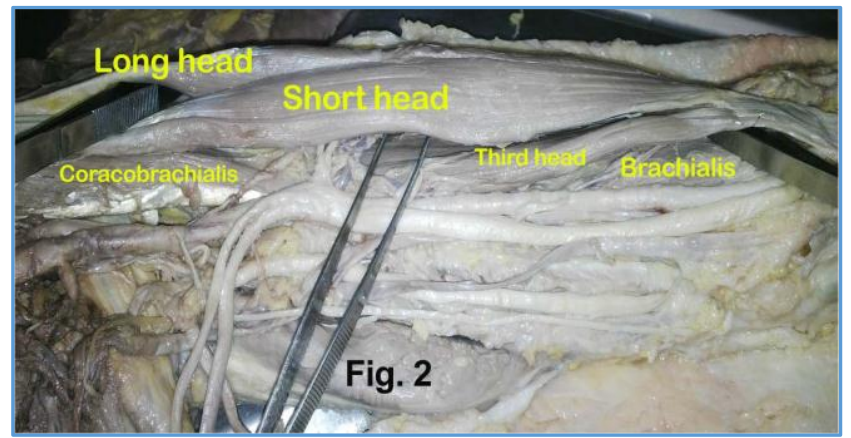

Figure 2. Its Origin was from Anteromedial Aspect of Humerus just below the Insertion of Coracobrachialis and Superomedial to Brachialis. The Length was $13.5 \mathrm{~cm}$.

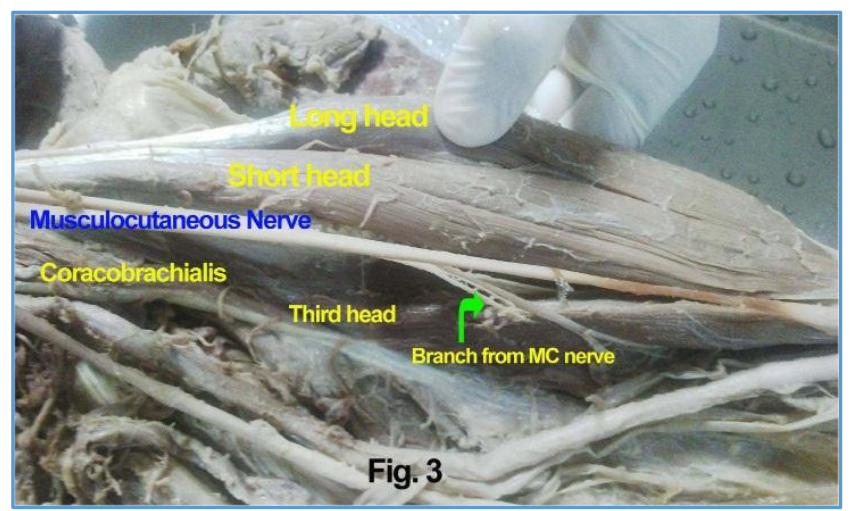

Figure 3. It was Innervated by the Branch from the Main Branch of Musculocutaneous Nerve

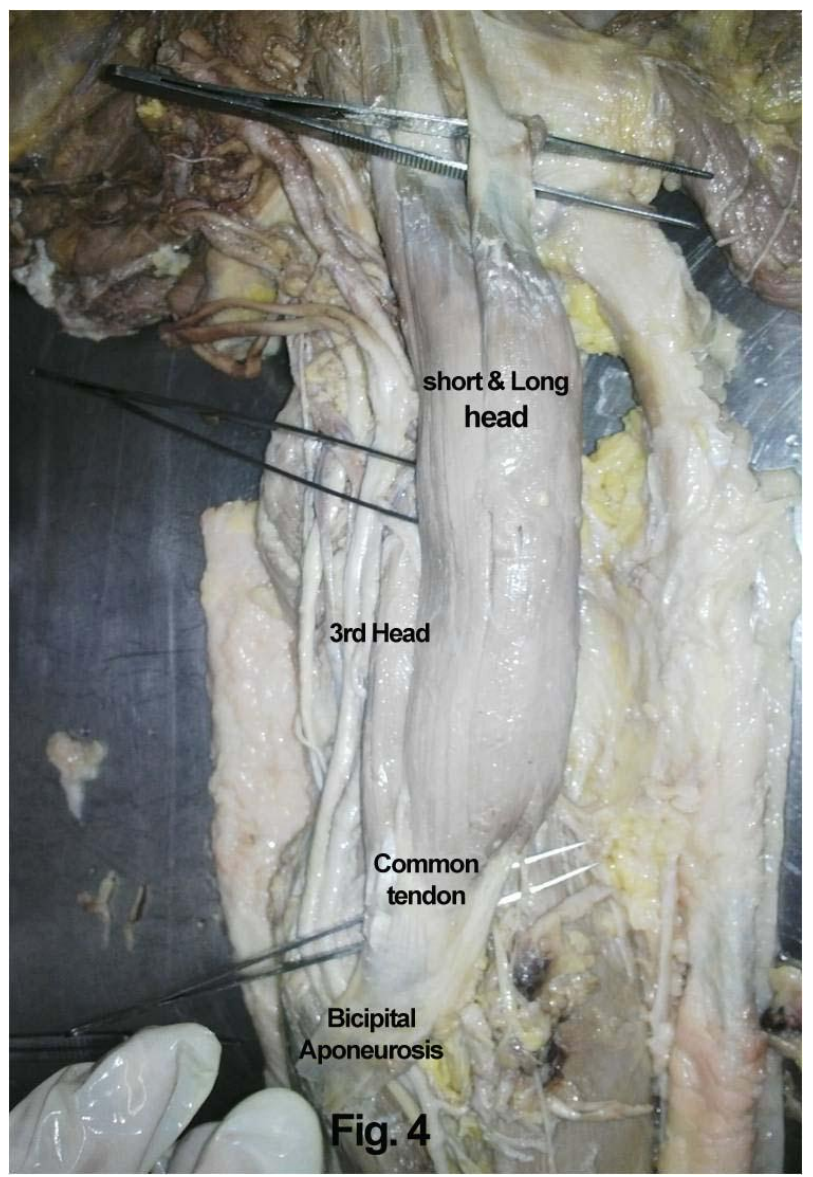

Figure 4. It Descended and Merged with the Other Two Heads to Form a Common Tendon and Inserted to Radial Tuberosity
In the rest of the limbs, it presented with the usual routine presentation.

\section{DISCUSSION}

Different authors have reported the incidence of the additional heads of the biceps brachii to be between $0.18 \%$ $21.5 \%$ in different population. ${ }^{4-19}$ The incidence in the present study being $1 \%$ which fits in the range with the previous studies.

\begin{tabular}{|c|c|c|}
\hline $\begin{array}{l}\text { Sl. } \\
\text { No. }\end{array}$ & Author & \begin{tabular}{|c|}
$\begin{array}{c}\text { Incidence of Third } \\
\text { Head of Biceps } \\
\text { Brachii. }\end{array}$ \\
\end{tabular} \\
\hline 1. & $\begin{array}{c}\text { Greig et al[4] } \\
\text { South African black }\end{array}$ & $21.5 \%$ \\
\hline 2. & $\begin{array}{l}\text { Bergman et al[5] } \\
\text { Chinese } \\
\text { European white } \\
\text { African black } \\
\text { Japanese }\end{array}$ & $\begin{array}{c}8 \% \\
10 \% \\
12 \% \\
18 \%\end{array}$ \\
\hline 3. & Khaledpour[6] & $0.18 \%$ \\
\hline 4. & Higashi and Sone ${ }^{[7]}$ & $18.3 \%$ \\
\hline 5. & Kosugi et al[8] & $12.5 \%$ \\
\hline 6. & $\begin{array}{c}\text { Asvat et al[9] } \\
\text { South African black } \\
\text { South African white }\end{array}$ & $\begin{array}{c}20.5 \% \\
8.3 \%\end{array}$ \\
\hline 7. & Williams et al[10] & $10 \%$ \\
\hline 8. & Nakatani et al[11] & $8 \%$ \\
\hline 9. & $\begin{array}{c}\text { Neto et al[12] } \\
\text { Brazilian white } \\
\text { Brazilian black }\end{array}$ & $\begin{array}{c}20 \% \\
9 \%\end{array}$ \\
\hline 10. & $\begin{array}{l}\text { Kopuz et al[13] } \\
\text { Turkish }\end{array}$ & $15 \%$ \\
\hline 11. & $\begin{array}{c}\text { Rincon et al[14] } \\
\text { Colombian population }\end{array}$ & $12.5 \%$ \\
\hline 12. & Ravindranath et al[15] & $1.8 \%$ \\
\hline 13. & Rai et al[16] & $7.1 \%$ \\
\hline 14. & Kumar et al[17] & $3.33 \%$ \\
\hline 15. & $\begin{array}{l}\text { Poudel and Bhattarai[18] } \\
\text { Nepalese } \\
\end{array}$ & $12.5 \%$ \\
\hline 16. & $\begin{array}{c}\text { Dr Prabhjot Cheema, Dr Rajan } \\
\text { Singla[19] }\end{array}$ & $2.3 \%$ \\
\hline 17. & Present study & $1 \%$ \\
\hline
\end{tabular}

According to the study done by Rai et al, ${ }^{16}$ with regard to the incidence in Indian population, it was reported to be $7.1 \%$. In the present study, it is $1 \%$ which is low when compared to their study.

The study done by Dr. Prabhjot Cheema and Dr Rajan Singla ${ }^{19}$ on the incidence of third head of biceps brachii in north Indian population was $2.3 \%$. In the present study, the incidence in the south Indian population is $1 \%$ which is less than theirs.

Sweiter and Carmichael ${ }^{20}$ emphasised that the incidence of additional heads of biceps brachii is more on the right side reflecting the fact that there were more right-handed people than the left handed and that the muscle fibre developed with use. In the present study, the third head of biceps brachii was on the left upper limb, may imply that the cadaver could be a left-handed person.

Dr Prabhjot Cheema and Dr Rajan Singla ${ }^{19}$ in their study reported three cases of third head of biceps brachii and all the three were found in the left upper limb and the study was 
done among north Indian cadavers. This finding is similar to the present study that the occurrence of the additional third head was from the left limb.

Asvat et $\mathrm{al}^{9}$ encountered the occurrence of the third head of biceps brachii more frequently in males. In the present study, the third head of biceps brachii was found in a male cadaver.

Kosugi et al ${ }^{8}$ in their study reported the average length of third head to be $13 \mathrm{~cm}$. Dr. Prabhjot Cheema and Dr Rajan Singla ${ }^{19}$ in their study reported the average length of the third head to be $12.9 \mathrm{~cm}$. In the present study, the third head that was found was measuring about $13.5 \mathrm{~cm}$ which is almost nearing the previously observed values.

The observed origin of third head of biceps brachii did not differ from that in the previously reported cases i.e. from the anteromedial surface of the shaft of the humerus, near the insertion of coracobrachialis and just above the origin of brachialis. ${ }^{9}$

In previous study by different authors, the accessory head was supplied by the musculocutaneous nerve, 8,9 which is similar to the present study. In the present study, it is supplied by a branch from musculocutaneous nerve.

The variations of the biceps brachii muscle phylogenetically were explained as a remnant of a tuberculoseptale head that together with the short and long heads, is present in Hylobates, but is a product of regression in humans and anthropoids. ${ }^{20}$

Sonntag 21 in his study described the third head of biceps brachii as a remnant of the long head of coracobrachialis, an ancestral hominoid condition, particularly in those cases where the third head arose from the insertional area of the coracobrachialis-which is same as the present study.

\section{CONCLUSION}

A variation in the heads of the biceps brachii muscle has already been reported to cause compression of surrounding neurovascular structures. It leads to erroneous interpretation during routine surgeries.

The presence of third head of biceps brachii muscle might increase its kinematics and also will increase the power of supination and flexion.

Such variation is not rare and is interesting not only for anatomists but also to orthopaedic surgeons, plastic surgeons, traumatologists, physiotherapists, doctors dealing with sports medicine and radiologists.

The existence of such variation should always be kept in mind by these clinicians when dealing with their patients.

\section{REFERENCES}

[1] Williams PL, Bannister LH, Berry MM, et al. Gray's anatomy: the anatomical basis of medicine and surgery. 38th edn. Edinburgh, ELBS: Churchill Livingstone 1995; p. 843.

[2] Sawant SP. The neurovascular compression due to the third head of biceps brachii in the right arm - a case report. World Research Journal of Anatomy 2013;1(1):04-06.

[3] Sargon MF, Tuncali D, Celik HH. An unusual origin for the accessory head of biceps brachii muscle. Clin Anat 1996;9(3):160-2.
[4] Greig WH, Anson BJ, Budinger JM. Variations in the form and attachments of the biceps brachii muscle. Quart Bull Northwestern Univ Med School 1952;26(3):241-4.

[5] Bergman RA, Thompson SA, Afifi AK, et al. Catalogue of human variation. Munich: Urban and Schwarzenberg 1984:27-30.

[6] Khaledpour VC. Uber Anomalien des M. biceps brachii. Anat Anz1985;159:79-85.

[7] Higashi N, Sone C. A study on the accessory head of the biceps brachii in man. Acta Anat Nippon 1988;63:7888.

[8] Kosugi K, Shibata S, Yamashita H. The supernumerary head of the biceps brachii and the branching pattern of the musculocutaneous nerve in Japanese. Surg Radiol Anat 1992;14(2):175-85.

[9] Asvat R, Candler P, Sarmiento EE. The high incidence of the third head of the biceps brachii in South African populations. J Anat 1993;182(Pt 1):101-04.

[10] Williams PL, Warwick R, Dyson M, et al. Myology. In: Gray's Anatomy. 37th edn. Great Britain: Churchill Livingstone 1989; p. 632.

[11] Nakatani T, Tanaka S, Mizukami S. Bilateral fourheaded biceps brachii muscles: the median nerve and the brachial artery passing through a tunnel which is formed by a muscle slip from the accessory head. Clin Anat 1998;11(3):209-12.

[12] Neto HS, Camilli JA, Andrade JC, et al. On the incidence of the third head of the biceps brachii in Brazilian whites and blacks. Ann Anat 1998;180(1):69-71.

[13] Kopuz C, Sancak B, Ozbenli S. On the incidence of the third head of the biceps brachii in Turkish neonates and adults. Kaibogaku Zasshi 1999;74(3):301-05.

[14] Rincon F, Rodriquez IZ, Sanchez A, et al. The anatomic characteristics of the third head of the biceps brachii in the Colombian population. Rev Chil Anat 2002;20(2):197-200.

[15] Ravindranath G, Jayasree N, Rajasree TK, et al. The three headed biceps brachii - a case report. J Anat Soc India 2005;54(1):70.

[16] Rai R, Ranade AV, Prabhu LV, et al. The third head of the biceps brachii in the Indian population. Singapore Med J 2007;48(10):929-31.

[17] Kumar H, Das S, Rath G. An anatomical insight into the third head of the biceps brachii muscle. Bratisl Lek Listy 2008;109(2):76-8.

[18] Poudel PP, Bhattarai C. A study on the supernumerary heads of the biceps brachii muscle in the Nepalese population. Nepal Med Coll J 2009;11(2):96-8.

[19] Cheema P, Singla R. Low Incidence of the third head of the biceps brachii in the North Indian population. Journal of Clinical and Diagnostic Research 2011;5(7):1323-6.

[20] El-Naggar MM, Zahir FI. Two bellies of the coracobrachialis muscle associated with a third head of the biceps brachii muscle. Clin Anat 2001;14(5):379-82.

[21] Sonntag CF. On the anatomy, physiology and pathology of the chimpanzee. Proc Zoo Soc 1923;22:323-63. 